\title{
Calorie 20 Degrees Celsius
}

National Cancer Institute

\section{Source}

National Cancer Institute. Calorie 20 Degrees Celsius. NCI Thesaurus. Code C68848.

A non-SI unit of energy defined as the amount of heat required to raise the temperature of one gram of pure water by one degree (from 19.5 to 20.5 C or from 292.65 to 293.65 K) under standard conditions with the specific heat of the water at 20 degrees Celsius and the constant pressure of $101.325 \mathrm{kPa}$ or one atm being defined as unity. A value defined for the calorie at 20 degrees Celsius is $4.1819 \mathrm{~J}$. According to the current national standard in the United States (IEEE/AST M SI 10T M 2002. American National Standard for Use of the International System of Units (SI): The Modern Metric System, New York: IEEE, 2002) the calorie in any form is not to be used. Joules should be used instead. 